\title{
Electrical anisotropy due to gas hydrate-filled fractures
}

\author{
Ann E. Cook ${ }^{1}$, Barbara I. Anderson ${ }^{2}$, Alberto Malinverno ${ }^{1}$, Stefan Mrozewski ${ }^{1}$, and \\ David S. Goldberg ${ }^{1}$
}

\begin{abstract}
In 2006, the Indian National Gas Hydrate Program Expedition 01, or NGHP-01, discovered gas hydrate as fill in nearvertical fractures in unconsolidated sediments at several drilling sites on the Indian continental margins. These gas hydrate-filled fractures were identified on logging-while-drilling resistivity images. The gas hydrate-filled fracture intervals coincide with high measured resistivity at the NGHP-01 sites. High measured resistivity translates into high hydrate saturations via Archie's equation; however, these high saturations contradict lower gas hydrate saturations determined from pressure core and chlorinity measurements. Also, in intervals with near-vertical gas hydrate-filled fractures, there is considerable separation between phase shift and attenuation resistivity logs, with $2-\mathrm{MHz}$ resistivity measurements being significantly higher than $400-\mathrm{kHz}$ resistivity measurements. We modeled the sensitivity of the propagation resistivity measurements in the gas hydrate-filled fracture intervals at NGHP-01 Sites 5 and 10. Near-vertical hydrate-filled fractures can cause the abnormally high resistivity measurements in vertical holes due to electrical anisotropy. The model suggests the gas hydrate saturations in situ are usually significantly lower than those calculated from Archie's equation. In addition, these modeled gas hydrate saturations generally agree with the lower gas hydrate saturations obtained from pressure core and chlorinity measurements at NGHP-01 Sites 5 and 10 .
\end{abstract}

\section{BACKGROUND}

In 2006, the Indian National Gas Hydrate Program Expedition 01 (NGHP-01) drilled, logged, and cored at 21 offshore sites to quantify natural gas hydrate deposits on India's continental margins as a po- tential energy resource (Collett et al., 2008). Natural gas hydrates are composed of highly concentrated natural gas and water and form under favorable temperature, pressure, and solubility conditions most often found in shallow, continental margin marine sediments (Kvenvolden and Barnard, 1982). Most of the NGHP-01 exploratory drill sites were located in the Krishna-Godavari (KG) basin on the eastern Indian continental margin, northeast of Chennai (Figure 1). Gas hydrate was clearly identified at 11 of the $15 \mathrm{KG}$ basin sites. While gas hydrate appeared in silt, sand, and ash at a few locations on the Indian continental margins, almost all of the gas hydrate in the KG basin occurred in clay-dominated sediments (Collett et al., 2008). At one site in the KG basin, NGHP-01 Site 10, over 120 m of high-resistivity section was recorded in the logs and attributed to natural gas hydrate (Collett et al., 2008; Lee and Collett, 2009). X-ray imaging of pressure cores from several KG sites, including Site 10, revealed natural gas hydrate occurring in a complex fracture plane network with both near-vertical fractures and horizontal features (Holland et al., 2008).

Five of the nine logging-while-drilling (LWD) holes drilled in the KG basin contain gas hydrate (Collett et al., 2008). All of these holes (Holes 5A, 5B, 6A, 7A, and 10A) depict gas hydrates residing primarily in near-vertical fracture planes on the LWD resistivity images (Cook and Goldberg, 2008a).

Gas hydrate residing in fracture planes has been noted in several marine locations worldwide, such as Blake Ridge offshore South Carolina, United States (Nimblett and Ruppel, 2003; Liu and Flemings, 2007); Hydrate Ridge offshore Oregon, United States (Hovland et al., 1995; Tréhu et al., 2003; Weinberger and Brown, 2006); the Gulf of Mexico (Sassen et al., 2001; Cook et al., 2008; Boswell et al., 2010); and offshore Korea in the Ulleung Basin (Chun et al., 2008; Holland et al., 2008). In general, fine-grained sediments tend to support gas hydrate in fracture or vein scenarios whereas coarsergrained sediments, like sands, usually incorporate natural gas hydrate in the sediment pore space (Clennell et al., 1999; Jain and Juanes, 2009).

Manuscript received by the Editor 5 January 2010; revised manuscript received 14 April 2010; published online 18 November 2010; corrected version published online 29 November 2010

${ }^{1}$ Borehole Research Group, Lamont-Doherty Earth Observatory, Palisades, New York, U.S.A. E-mail: acook@1deo.columbia.edu; alberto@1deo.columbia. edu; stefan@1deo.columbia; goldberg@1deo.columbia.edu.

${ }^{2}$ Consultant, Brookfield, Connecticut, U.S.A.E-mail: anderson2@slb.com.

(c) 2010 Society of Exploration Geophysicists. All rights reserved. 


\section{Evaluating gas hydrate with well logs and cores}

During NGHP-01, both wireline-logged and LWD holes were drilled in the KG basin. All NGHP-01 holes are intended to be vertical holes and likely deviate a degree or less. A description of the NGHP-01 logging procedures can be found in Collett et al. (2008).

Resistivity logs are used to identify and quantify gas hydrate because gas hydrate is an electrical insulator and increases measured resistivity if present in the sediment system. Archie's equation, which relies on a comparison of the measured porosity and resistivity, has been used for decades in the petroleum industry to assess saturations of oil and gas in the pore space of rocks (e.g., Ellis and Singer, 2007) and is commonly used to calculate gas hydrate saturation (e.g., Hyndman et al., 1999; Collett and Ladd, 2000; Collett and Lee, 2000; Collett, 2001; Collett et al., 2008; Malinverno et al., 2008).

During NGHP-01, resistivity was measured with the Dual Induction Spherically Focused Resistivity Tool (DIT) in wireline-logged holes. In Archie calculations for wireline-logged holes, we use the shallow spherically focused resistivity SFLU from the DIT tool because it provides the best vertical resolution $(\sim 60 \mathrm{~cm})$ of any of the available wireline resistivity measurements. In the NGHP-01 LWD bottom hole assembly, the geoVISION ${ }^{3}$ imaging-while-drilling tool provides $360^{\circ}$ resistivity images that are used to identify the orientation of gas hydrate-filled fractures. In addition, the geoVISION measures a suite of laterolog-type resistivities, of which the RING resistivity is used for Archie calculations because of its high vertical resolution $(5 \mathrm{~cm})$ and relatively deep radial measurement $(18 \mathrm{~cm})$. In addition, the LWD EcoScope ${ }^{3}$ tool provides propagation resistivity measurements, which are used later in this paper for 1D anisotropy modeling.

\section{Determining hydrate saturation}

Gas hydrate saturation is the fraction of pore space occupied by gas hydrate. The term "saturation" may be somewhat of a misnomer in gas hydrate-filled fracture systems, since the gas hydrate may concentrate chiefly in the fractures and not in the primary pore space within the sediment grain infrastructure. In this paper, we retain the convention and report gas hydrate as a saturation, but note that gas hydrate saturation $S_{h}$ converts to gas hydrate volume $V_{h}$ with knowledge of the porosity $S_{h}=V_{h} / \phi$.

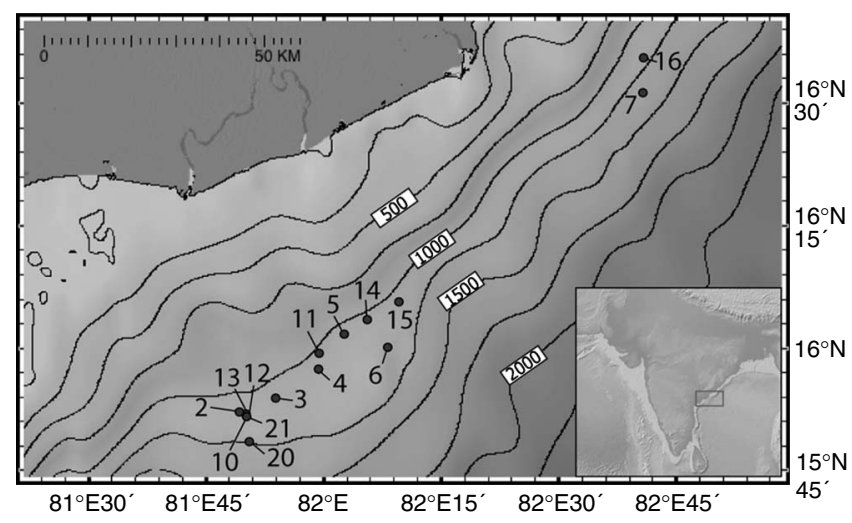

Figure 1. Location of NGHP-01 Sites in the KG Basin, offshore eastern India.
Archie (1942) first recognized the relationship between the measured resistivity $R_{t}$ and the amount of electrical insulator in the pore space. Modifications of Archie's equation are often used in shales or clay-rich sediments because clay ions contribute to the bulk conductivity. However, this conductivity increase does not affect measurements in high-porosity clays (Erickson and Jarrard, 1998) like those occurring in the KG Basin.

To determine which sections of a log are hydrate bearing, we first calculate the predicted water-saturated resistivity $R_{o}$ (the resistivity of the sediments with no hydrate present). $R_{o}$ is defined as

$$
R_{o}=\frac{a R_{w}}{\phi_{\mathrm{den}}^{m}},
$$

where $R_{o}$ is the formation resistivity when water-saturated, $a$ is the Archie tortuosity coefficient, $R_{w}$ is the formation water resistivity at reservoir temperature and pressure, $m$ is the Archie cementation exponent, and $\phi_{\text {den }}$ is the porosity calculated from density.

The resistivity of the pore water $R_{w}$ is calculated using a combination of pressure, downhole temperature, and background salinity. Density porosity $\phi_{\text {den }}$ is calculated from the in situ density log, pore water density, and grain density. The values $a$ and $m$ from equation 1 are determined by selecting sections of the $R_{t} \log$ (RING or SFLU resistivity) that are water-saturated and of good data quality, and then matching $R_{o}$ to $R_{t}$. For example, in Hole $5 \mathrm{~A}$ the depth intervals from 40 to $50 \mathrm{~m}$ below seafloor (mbsf) and from 120 to $180 \mathrm{mbsf}$ were selected as water-saturated (Figure 2). Best-fit $a$ and $m$ values are then applied to the entire logged hole. NGHP-01 $a$ and $m$ values used in this paper are reported in Cook (2010). Sections in the log where $R_{t}$ is greater than $R_{o}$ indicate the presence of gas hydrate. In this paper, we refer to an interval where $R_{t}$ exceeds $R_{o}$ as a hydrate-bearing interval (HBI). In Hole 5A, a HBI occurs from 56 to 95 mbsf (Figure 2), in Hole 5B from 56 to 91 mbsf, and in Hole 10A from 27 to 158 mbsf.

The hydrate saturation is estimated from the ratio of $R_{o}$ to $R_{t}$ and an empirical saturation exponent $n$ :

$$
S_{h}=1-\left(\frac{R_{o}}{R_{t}}\right)^{1 / n},
$$

where $S_{h}$ is the hydrate saturation, $R_{t}$ is the true formation resistivity, and $n$ is the Archie saturation exponent.

The saturation exponent $n$ depends on the conductivity of brine in the sediment pore space, sediment grain microstructure, and hydrate saturation history (Spangenberg, 2001). Typically, $n=2$ is applied in oil and gas reservoirs (Ellis and Singer, 2007). Gas hydrate studies and models have suggested several values of $n$ for various unconsolidated sediments: $n \approx 2$ (Pearson et al., 1983), $n$ ranging from 0.5 to 4.0 (Spangenberg 2001), $n=1.6$ (Santamarina and Ruppel, 2008), and $n=2.4 \pm 0.3$ (Malinverno et al., 2008). Figure 2 displays saturation curves calculated for Hole 5A where $n$ equals 1.5 and 2.5. In the HBI from Hole 5A, the values of $n=1.5$ and $n=2.5$ produce, at most, a difference in saturation of $10 \%$. In this paper, we use $n=2$ as midrange value for comparison with other hydrate saturation techniques.

Hydrate saturation can also be determined through various corebased techniques. Pressure cores are meter-long sediment cores that

\footnotetext{
${ }^{3}$ Mark of Schlumberger.
} 
are sealed in situ (Kvenvolden et al., 1983; Dickens et al., 2000). In a successful pressure core, temperature and pressure fluctuations must remain within the required bounds for hydrate stability during core recovery and the core must remain sealed. Later, when the core is depressurized, the volume of natural gas within the pressure core is measured. Hydrate saturation is calculated from the collected gas volume and knowledge of the sediment porosity as well as in situ pressure, temperature, and salinity (Collett et al., 2008; Schultheiss et al., 2008). As long as gas hydrate is preserved in the pressure core and no gas leaks, gas hydrate saturation estimates from pressure cores are highly accurate; errors in gas hydrate saturation calculated via pressure cores are likely less than $0.5 \%$ by pore volume (Holland, 2008, personal communication). Twentyeight successful pressure cores were collected in the KG basin. Typically, one or two successful pressure cores were collected in each of the cored holes.

Pore water measurements of chlorinity provide another estimate of hydrate saturation (Ussler and Paull, 1995). When gas hydrate forms within the marine sediment, the crystal structure excludes ions, such as chlorine, which diffuse through the sediment over time. When a core containing gas hydrate is collected, the gas hydrate dissociates as the core is pulled up through the drill pipe and on deck, releasing gas into the air and fresh water into the sediment (Hesse and Harrison, 1981). Pore water measurements are collected from 10 $-\mathrm{cm}$ sections of the core after it has been recovered. Hydrate saturation can be calculated based on the degree of pore water freshening and the estimated background salinity in situ (Ussler and Paull, 1995), with only a small correction for the volume change during gas hydrate dissociation (Ussler and Paull, 2001). However, chlorinity measurements can only accurately determine hydrate saturation if all of the excess chlorinity generated from hydrate formation has diffused away, so saturations may not be reliable in all cases.

Figures 3 and 4 display the hydrate saturations calculated using Archie's equation $(n=2)$, pressure core degassing, and chlorinity measurements for NGHP-01 Sites 5 and 10. When comparing only the pressure core and chlorinity measurement saturations in each hole, both methods suggest similar lower hydrate saturations, which helps to corroborate both measurements. In contrast, the hydrate saturation calculated from Archie's equation is much higher than saturations from pressure cores and the chlorinity measurements. For instance, in Hole 5D, application of Archie's equation to the SFLU resistivity log yields gas hydrate saturations near $30 \%$ in the interval from 75 to 85 mbsf. However, pressure cores from Hole 5D suggest only 5-9\% gas hydrate satura-
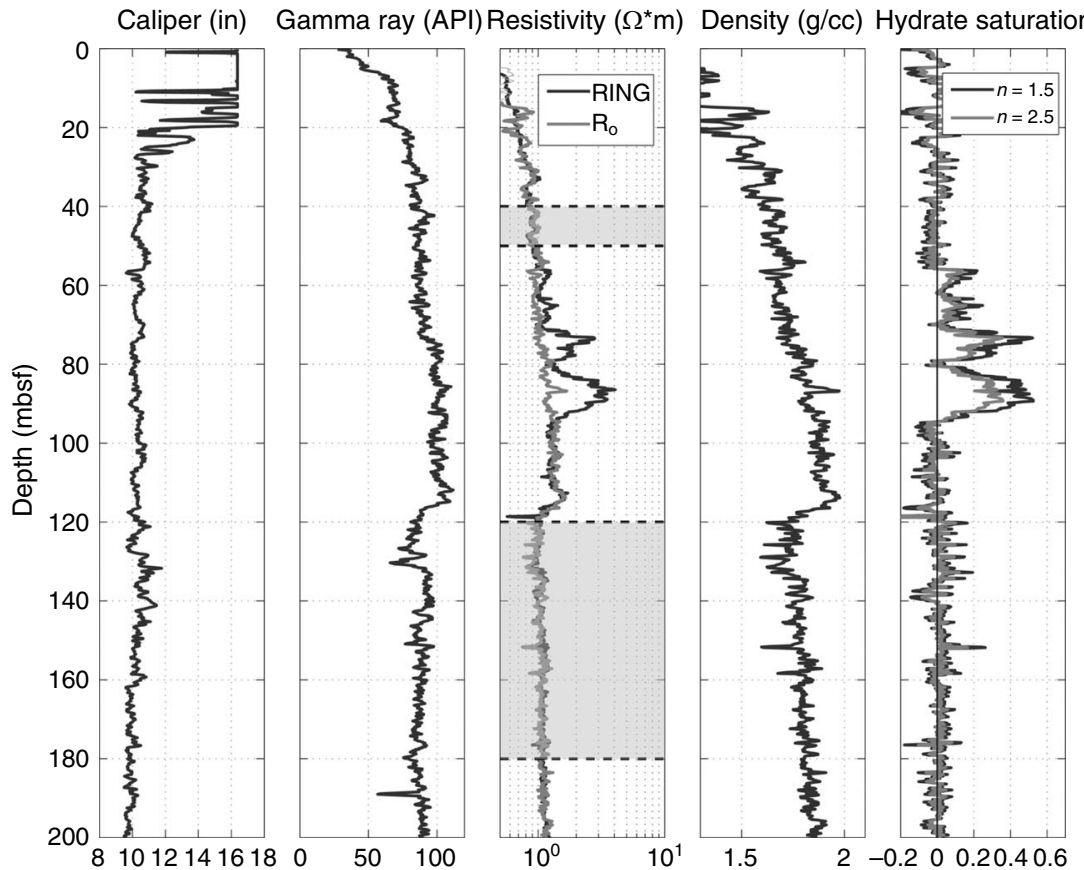

Figure 2. Example of Archie equation applied to the logs from NGHP-01 Hole 5A. The caliper log (track 1) indicates that most of the hole below $30 \mathrm{mbsf}$ is close to the bit size, approximately 9 inches. Thus, most of the hole is in good condition. To calculate hydrate saturation, water-saturated intervals are selected that (1) have good hole condition and (2) show no indication of gas hydrate (i.e., no increase in resistivity). Dashed lines highlight these intervals in track 3 . In the water-saturated intervals, the density log (track 4) is matched to the measured RING resistivity, and the Archie parameter $a$ and $m$ values are determined for Hole 5A. The predicted water-saturated resistivity $R_{o}$ is then calculated for the entire hole. Hydrate saturation is calculated from the ratio of the $R_{o}$ curve to the RING resistivity curve. Hydrate saturation is displayed as a fraction of the pore space on the last track. $n=$ Archie's saturation exponent

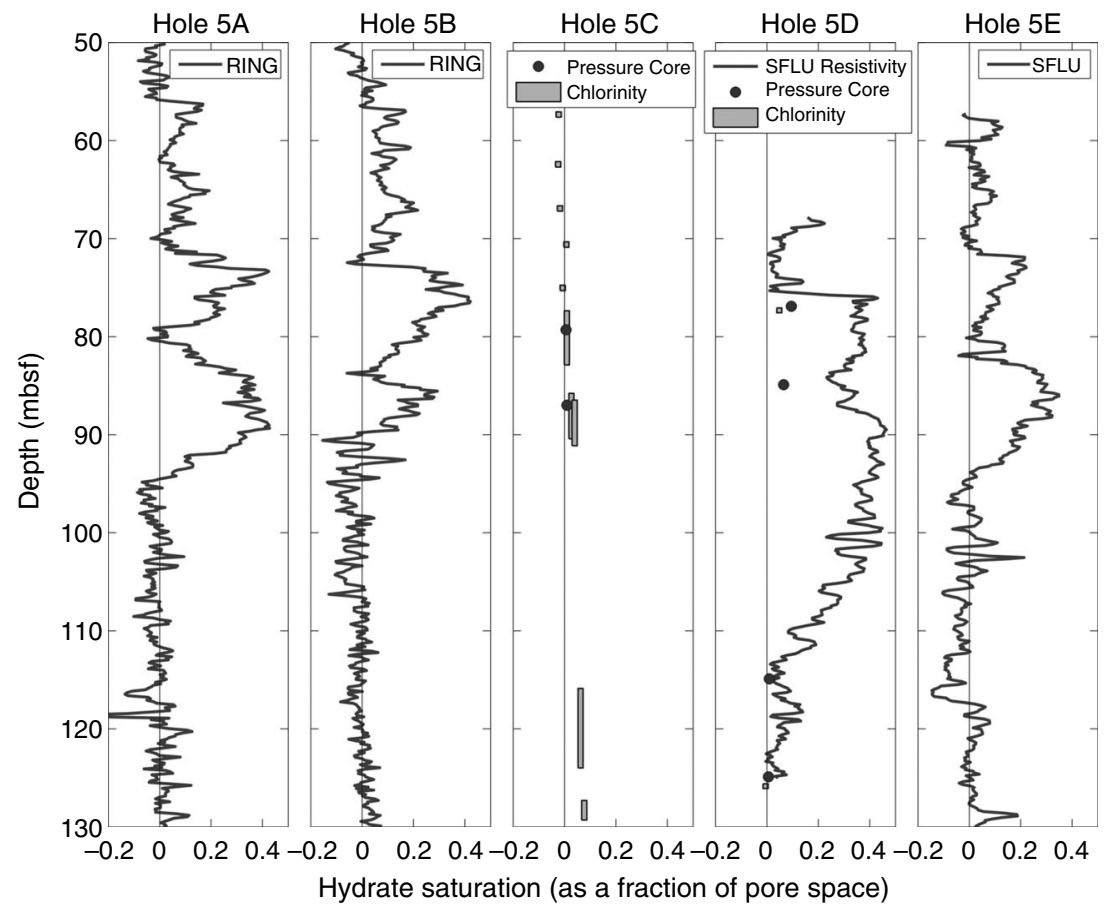

Figure 3. Comparison of gas hydrate saturation calculated from resistivity, pressure cores, and chlorinity measurements from all holes at NGHP-01 Site 5. The length of the chlorinity box indicates the depth uncertainty of the measurement: the longer the box, the larger the depth uncertainty. 
tions between 75 to $85 \mathrm{mbsf}$, and pressure cores and chlorinity measurements in the same interval from Hole $5 \mathrm{C}$ indicate only $1-2 \%$ gas hydrate saturation.

At Site 10, Archie's equation calculated hydrate saturations two to five times higher than the average estimates from pressure cores and chlorinity measurements. Only two chlorinity measurements from Hole 21A appear to corroborate any of the high $(>80 \%)$ saturations calculated from 40 to $90 \mathrm{mbsf}$ in Hole 10A. The other chlorinity measurements, as well as the recovered pressure core from Hole $21 \mathrm{~A}$, suggest that the interval from 40 to $90 \mathrm{mbsf}$ has significantly lower saturations.

If we apply $n$ to match Archie's saturation calculation and the pressure core saturations in Hole 5D, $n$ must be raised to 10 , far higher than any laboratory-calculated and modeled values have suggested. An extremely high saturation exponent of $n=12$ best matches Archie's saturation calculation to the pressure cores and chlorinity measurements in Hole 10D. Simply applying large $n$ values to bulk shift the gas hydrate saturation lower does not seem to be a realistic solution because it is not corroborated by laboratory measurements or modeling.

Thus, Archie's equation does not appear to correctly assess the amount of gas hydrate in situ in Sites 5 or 10. The difference in satunear-vertical fractures. We selected $\mathrm{KG}$ basin Holes 5A, 5B, and $10 \mathrm{~A}$ to analyze the variability among hydrate saturation estimates and the effect of vertical fractures on measured resistivity. Hole 10A was selected because of the extremely high resistivity and extensive gas hydrate-filled fracture network. Holes 5A and 5B were chosen to represent more moderate gas hydrate-filled fracture systems, similar rations is likely due to the way that the gas hydrate forms - as fill in

to Holes $6 \mathrm{~A}$ and $7 \mathrm{~A}$. In addition, Site 5 contains five drilled holes, chlorinity measurements, and several pressure cores for gas-hydrate saturation comparisons (Figure 3).

\section{GAS HYDRATE-FILLED FRACTURES}

In Holes 5A, 5B, and 10A, high-angle gas hydrate-filled fractures are visible in the recorded LWD resistivity images. Oriented LWD images represent a $360^{\circ}$ resistivity measurement of the borehole wall. On the images, dipping planar features appear as sinusoids (Figure 5). For a fracture to be identified on an image, the fracture must exhibit a higher or lower resistivity than the surrounding sediment system. It may be impossible to identify gas hydrate-filled fractures in a massive gas hydrate layer, within concentrated clusters of fractures, or in intervals where gas hydrate is disseminated in pore space due to reduced resistivity contrast.

All visible fractures were selected from the resistivity images in Holes 5A, 5B, and 10A, and the strike and dip of each fracture was calculated (Figure 5). The fracture orientations for all NGHP-01 sites are reported in Cook (2010). The finite resolution of an image adds $\pm 6^{\circ}$ of uncertainty to the strike. Dips greater than $70^{\circ}$ have less than \pm 1 degree uncertainty. It is impossible to know the thickness of fractures from the LWD images because the angle of fracture dip and the resistivity of the fracture distorts the size of the fracture on the image, although the fractures are likely only a few millimeters to a centimeter in scale. Orientations for features dipping at angles lower than $10^{\circ}$ cannot be accurately resolved. In addition, flat-lying features millimeters in thickness may not be fully resolved by the measurement or may not be detected.

In all holes from NGHP-01, gas hydrate-filled fractures tend to be

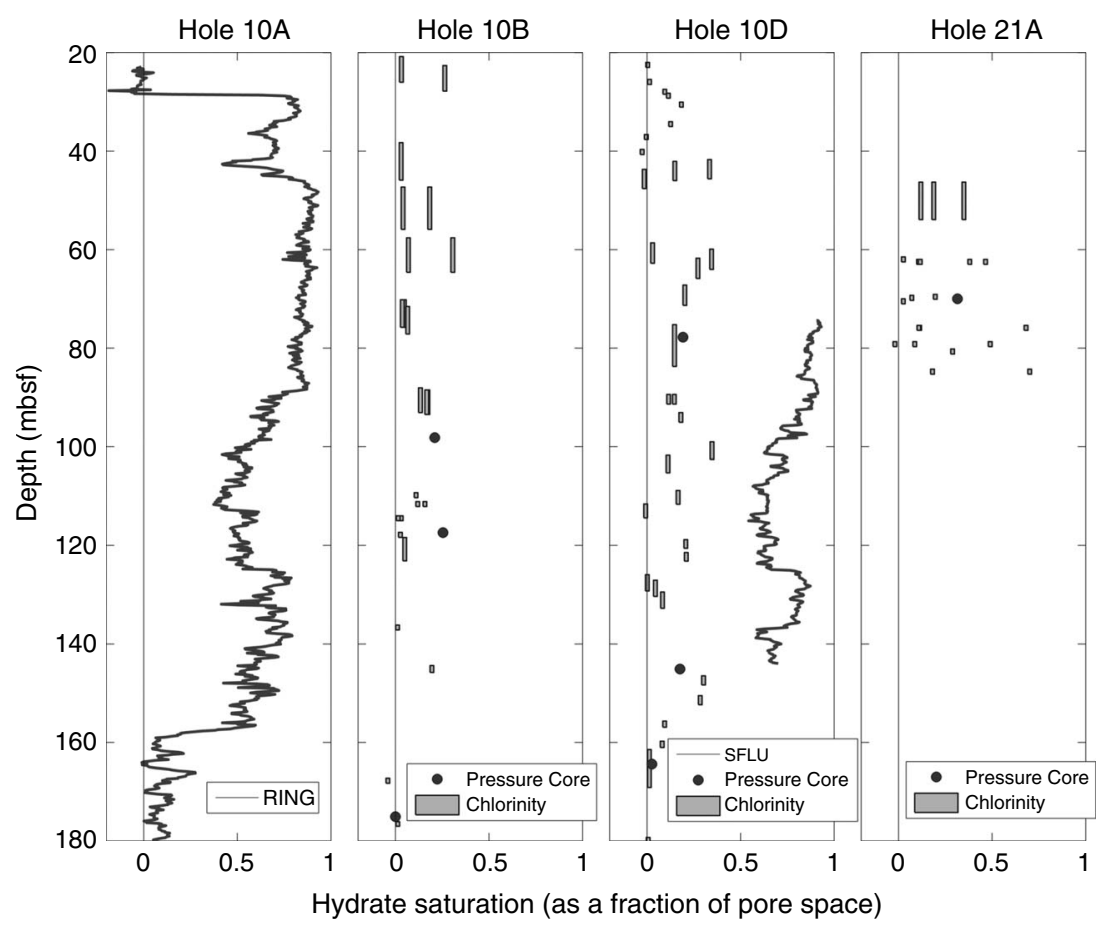

Figure 4. Comparison of gas hydrate saturation calculated from resistivity, pressure cores, and chlorinity measurements from all holes at NGHP-01 Site 10 and NGHP-01 Hole $21 \mathrm{~A}$ (a hole $\sim 20 \mathrm{~m}$ southeast of Hole 10A). The length of the chlorinity box indicates the depth uncertainty of the measurement: the longer the box, the larger the depth uncertainty. high-angle, between $60^{\circ}$ and $90^{\circ}$, and coincide with the HBI in all holes. At Sites 5 and 10, selected fractures suggest a fracture occurrence of approximately $1-1.5$ fractures $/ \mathrm{m}$; however, actual fracture occurrence is most likely higher because only clearly visible fractures are counted. All fractures identified in Holes 5A, 5B, and 10A are plotted as poles to the fracture planes on lower hemisphere equal area stereonets (Figure 6). Most of the poles lie near the circumference of the stereonet, which indicates high-angle fractures. The poles on the stereonets for Holes 5A and 5B are tightly clustered in the northeast quadrant, suggesting a system of parallel fractures. Fracture orientations from Hole 10A are more broadly distributed, indicating that the fracture pattern at Site 10 is not as well ordered as Site 5 (Figure 6).

At Hydrate Ridge, drilled during Ocean Drilling Program Leg 204, significant lateral variability in gas hydrate occurrence was observed in holes only tens of meters apart (Tréhu et al., 2006). Because NGHP-01 fractures are nearly vertical, it seems impossible to compare hydrate saturation holes even $10 \mathrm{~m}$ apart. However, Cook and Goldberg (2009b) show that gas hydratefilled fractures at NGHP-01 Site 5 likely occur as a layer in the middle of the gas hydrate stability zone. More recently, the Gas Hydrate Joint Industry Project Leg II identified near-vertical gas hydrate-filled fractures within a stratigraphically 
bound layer that extended laterally over a kilometer in the Gulf of Mexico (Boswell et al., 2010). Even if NGHP-01 fractures are not occurring in a layer, in two holes (Hole 5D and Hole 10D) logs, pressure cores, and chlorinity measurements were collected. In those holes, Archie's saturations substantially exceed the saturations estimated by the pressure core and the chlorinity measurements (Figures 3 and 4). Although intrasite variability may exist at NGHP-01 Sites 5 and 10 , it is very likely that Archie's equation significantly overestimates the hydrate saturation in each hole.

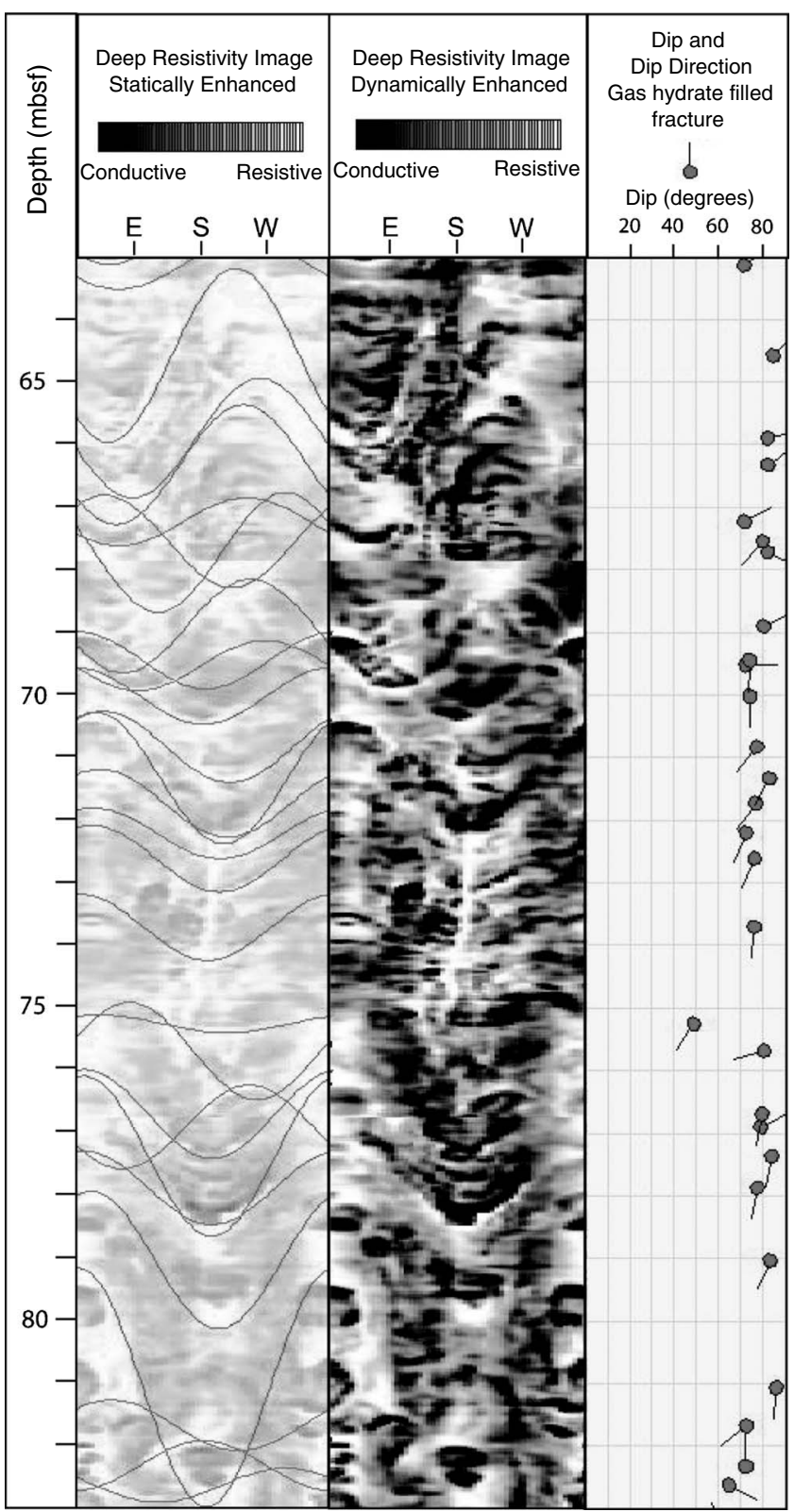

Figure 5. A section of the $360^{\circ}$, unwrapped, LWD borehole resistivity image from NGHP-01 Hole 10A. Selected fractures are highlighted on the statically enhanced image with thin gray lines. Images are normalized over the entire hole depth (static normalization) and over 2 -m bins (dynamic normalization) to aid in image analysis. The calculated dip of each fracture is plotted as a dot and the cardinal dip direction is indicated by the tail direction.
After analyzing the hydrate saturations and fractures at Site 5 and Site 10, we suggest that electrical anisotropy, a directionally dependent variation in resistivity, caused the high measured resistivities in the gas hydrate-filled fracture intervals. In anisotropic environments, propagation resistivity measurements exhibit significantly different resistivity values for different source and receiver spacings. We model LWD propagation resistivity measurements, which are particularly sensitive to electrical anisotropy, to understand the response of propagation resistivity in high-angle gas hydrate-filled fractures and to determine gas hydrate saturation.

\section{ELECTRICAL ANISOTROPY IN WELL LOGGING}

In a vertical well with horizontal beds, propagation and RING resistivity logs measure the electrical resistivity normal to the borehole and parallel to the bedding, $R_{\|}$, and they are insensitive to the electrical resistivity perpendicular to the beds, $R_{\perp}$. In this geometry, $R_{t}$ effectively equals $R_{\|}$. However, if the tilt of the beds changes relative to the borehole, due to well deviation or dipping beds, $R_{t}$ becomes a combination of $R_{\|}$and $R_{\perp}$ (Figure 7). As the angle between the borehole and the bedding increases, $R_{\perp}$ becomes an increasingly significant component of the measured resistivity. As the $R_{\perp}$ component increases, the measured resistivity rises because $R_{\perp}$ is always greater than $R_{\|}$in a layered/laminated environment. $R_{\|}$reflects the resistivity as if the beds are resistors in parallel, and $R_{\perp}$ reflects the resistivity as if the beds are resistors in series. For example, in an alternating sequence of flat-lying laminated beds of the same thickness, with one bed at $1 \Omega \mathrm{m}$ and the other at $100 \Omega \mathrm{m}, R_{\|}$would be equal $2 \Omega \mathrm{m}$, while $R_{\perp}$ would be $50 \Omega \mathrm{m}$.

For many decades, only vertical wells were drilled in oil and gas fields where bedding was usually horizontal or nearly horizontal; thus, $R_{\|}$chiefly affected the measured resistivity. Archie's equation was developed using logging data where only $R_{\|}$was measured (Archie, 1942; Kennedy et al., 2001). When deviated and horizontal wells became common in the 1980s, it was discovered that techniques developed for vertical wells could not be applied in the cases of high-angle or horizontal wells due to the influence of $R_{\perp}$ (Leake and Shray, 1991; Ellis and Singer, 2007). The NGHP-01 holes contain near-vertical fractures, which can be approximated as near-ver-

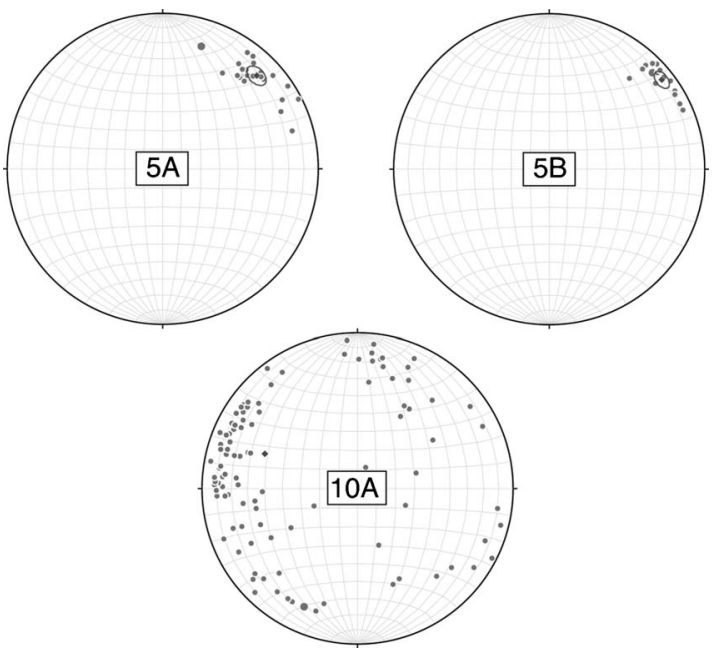

Figure 6. Poles to the gas hydrate-filled fracture planes for NGHP-01 Holes 5A, 5B, and 10A plotted on a lower hemisphere equal area stereonet. 
tical, resistive planes. This means that, like near-horizontal beds in a horizontal well, the NGHP-01 holes are strongly influenced by $R_{\perp}$ (Figure 7a).

Lee and Collett (2009) used modeling techniques from Kennedy and Herrick (2004) to compare the effects of horizontal and vertical resistive fractures on Archie parameters $n$ and $m$ in an attempt to minimize the effect of electrical anisotropy on calculated hydrate saturations. Lee and Collett (2009) estimated $m=2$ and $n=3$ for NGHP-01 Site 10 based on wireline velocity data from Hole 10D. However, Lee and Collett acknowledge that these $m$ and $n$ values
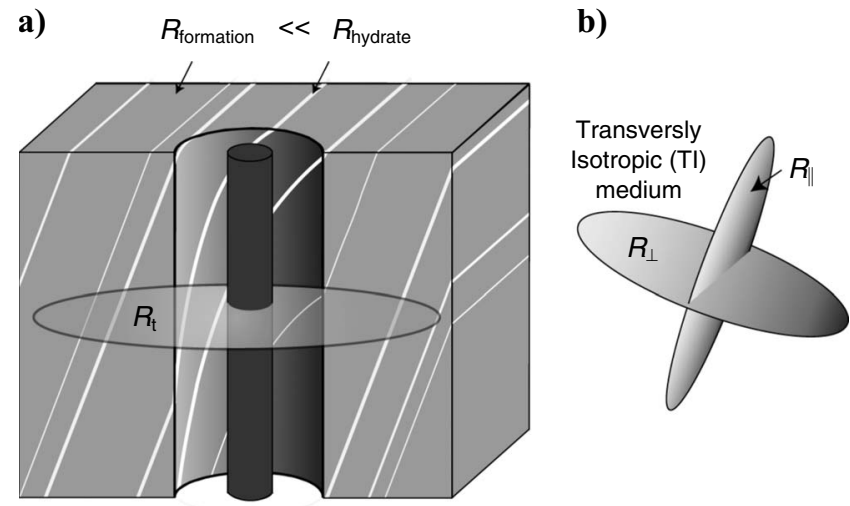

Figure 7. (a) An idealized model of resistivity measurements in a high-angle gas hydrate-filled fracture system. $R_{t}$ indicates the approximate range of the resistivity measurement in a vertical borehole with high-angle fractures. (b) The TI medium and the direction of $R_{\|}$ and $R_{\perp}$ for the idealized model.

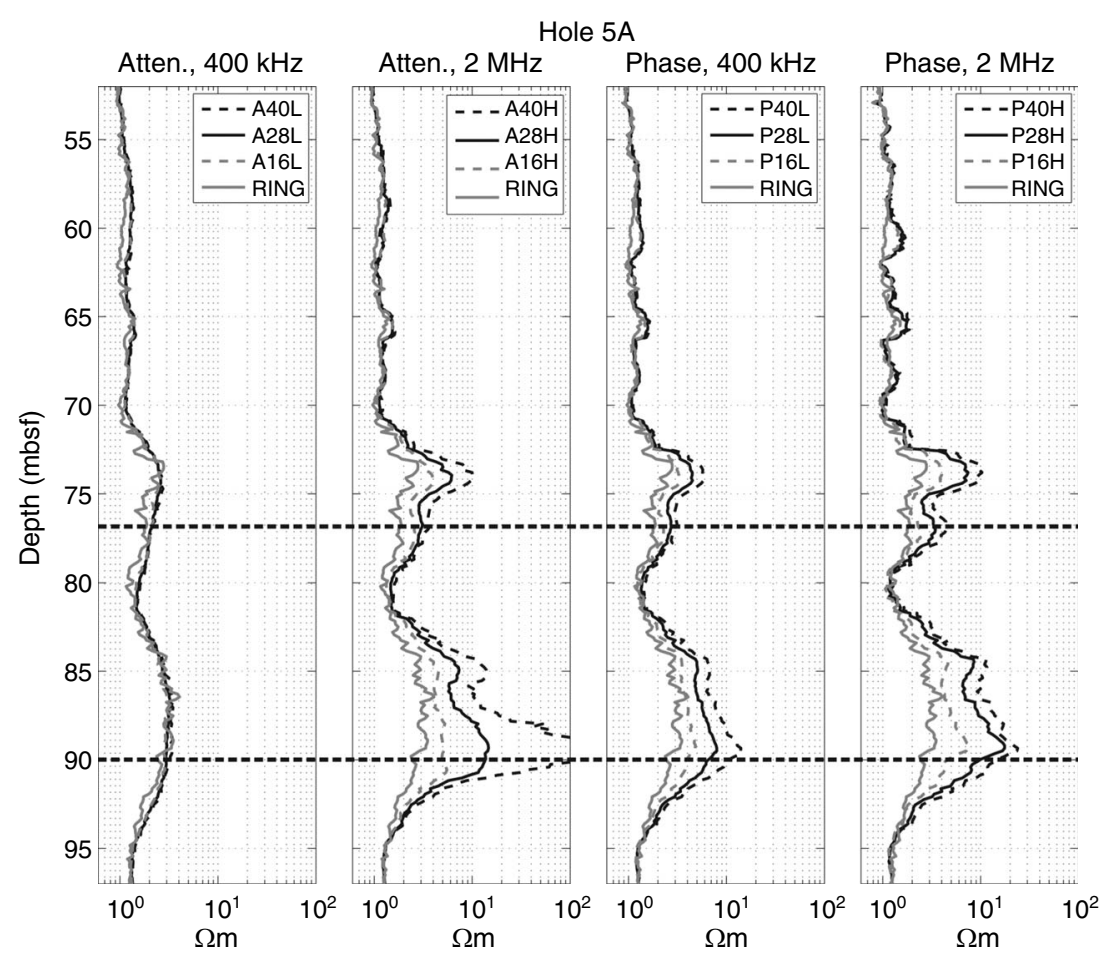

Figure 8. Propagation resistivity curves measured in NGHP-01 Hole 5A. Gas hydratefilled fractures were identified from 61 to $92 \mathrm{mbsf}$, which coincides with propagation curve separations. Depths highlighted with thick dashed lines were modeled. should not be directly applied to Holes $10 \mathrm{~A}$ and 10D because there are still large differences between the pressure cores and Archie's equation saturations using the modified parameters. This is similar to our previous attempt to adjust $n$ to match gas hydrate saturation from pressure cores and chlorinity measurements: $n$ had to be greater than 10 to match the gas hydrate saturation measured from pressure cores.

Thus, because Archie's equation was developed and refined in effectively isotropic lithology, using Archie's equation or modified Archie parameters may not be the best approach to appraise gas hydrate saturation in near-vertical gas hydrate-filled fractures.

\section{Propagation resistivity measurements}

The set of propagation resistivity measurements collected at different frequencies and different transmitter and receiver antenna spacings are particularly sensitive to electrical anisotropy. The propagation resistivity tool measures the propagation of an electromagnetic wave; two independent resistivity estimates of the formation are generated based on the phase shift and attenuation of the wave (for more description, see Ellis and Singer, 2007). LWD propagation resistivity tools generate electromagnetic waves at $400 \mathrm{kHz}$ and $2 \mathrm{MHz}$ with transmitter and receiver antennas at five different spacings between 16 and 40 inches. The depth of investigation into the formation adjacent to the borehole increases as the transmitter and receiver spacing increases and as the measurement frequency decreases. However, the transform applied to the phase shift and attenuation of the electromagnetic wave to determine resistivity assumes isotropic resistivity.

In the gas hydrate-filled fracture intervals in Holes 5A and 5B, the attenuation resistivity measured at $2 \mathrm{MHz}$ and the phase-shift resistivity measured at $400 \mathrm{kHz}$ and $2 \mathrm{MHz}$ display a significant separation between curves recorded at different transmitter and receiver spacings (Figures 8 and 9). The curve separation increases with the size of the antenna spacing, which is indicated in inches by the number between $\mathrm{A}$ or $\mathrm{P}$ (attenuation or phase) and L or $\mathrm{H}$ (indicating a low-frequency $400-\mathrm{kHz}$ measurement or a high-frequency 2-MHz measurement). For example, P28L represents a phase-shift measurement made at $400 \mathrm{kHz}$ and 28-inch source and receiver spacing.

Propagation resistivity measurements are insensitive to resistive thin beds or fractures that are exactly perpendicular to the borehole (Lüling et al., 1994). But as the orientation of the resistive fracture becomes more parallel to the borehole, propagation resistivity measurements become sensitive to the horizontal and vertical resistivity, measuring a weighted average of $R_{\|}$and $R_{\perp}$, even for thin beds. For example, at dip angles of a resistive fracture greater than $60^{\circ}$, the attenuation resistivity measurement is more influenced by $R_{\|}$, while the phase-shift measurements are more dependent on $R_{\perp}$. A significant contrast between $R_{\|}$ and $R_{\perp}$ has been shown to cause curve separation between propagation resistivity measurements at different depths of investigation (Lüling et al., 1994; Anderson, 2001; Ellis and Singer, 2007). In 
general, phase-shift resistivity measurements are more sensitive to vertical features while attenuation measurements are more sensitive to horizontal features, but both are affected by changing orientations of $R_{\|}$and $R_{\perp}$ (Anderson, 2001).

Hole 10A (Figure 10) exhibits resistivity measurements and curve separations significantly higher than at Site 5 (Figures 8 and 9). In Hole 10, curve separation appears in the attenuation resistivity curves measured at $2 \mathrm{MHz}$ and the phaseshift resistivity curves measured at $400 \mathrm{kHz}$ and $2 \mathrm{MHz}$. However, this separation only occurs in the phase-shift curves from 28 to $43 \mathrm{mbsf}$ and from 90 to 155 mbsf. The interval in between, from 43 to $90 \mathrm{mbsf}$, displays spiky and blocky response in the attenuation measurements and no curve separation for the phase-shift measurements. The flat response in the phase-shift curves may indicate pore-filling or solid gas hydrate occurring over the 43- to 90-mbsf interval. In addition, many of the measured resistivity curves in Hole 10A exceed the accuracy range for the propagation resistivity measurements (Table 1 ) and logs may not be producing accurate resistivities in the interval from 43 to 90 mbsf. Due to these issues, we only model the curve separation in Hole 10A for the interval below $90 \mathrm{mbsf}$.

Propagation resistivity curve separations also occurred at NGHP-01 Sites 6 and 7 within intervals containing gas hydrate-filled fractures. More recently, propagation curve separations were also identified in gas hydrate-filled fracture intervals at two sites in the Gulf of Mexico during the Chevron/U.S. Department of Energy gas hydrate Joint Industry Drilling Project Leg 2 (Cook et al., 2010; Guerin et al., 2010).

\section{ANISBEDS MODELING}

To determine how near-vertical gas hydratefilled fractures affect resistivity measurements, we use ANISBEDS, a 1D numerical forward modeling code (Lüling et al., 1994). The code was originally developed to evaluate thinly laminated hydrocarbon-bearing formations (i.e., conductive shales interbedded with resistive, hydrocarbon-rich sands) in deviated holes (Lüling et al., 1994). The code models the electric and magnetic fields generated in dipping laminated layers by an arbitrarily oriented magnetic dipole transmitter. In addition, the code assumes a transversely isotropic (TI) medium (Figure 7b). In a TI medium, a constant resistivity is assumed parallel to the bedding laminations or fractures, called $R_{\|}$. A different isotropic resistivity occurs perpendicular to the bedding planes or fractures, $R_{\perp}$. Because $R_{\perp}$ reflects the resistivity as if the beds were resistors in series, $R_{\perp}$ is larger than $R_{\|}$. The larger the difference between $R_{\|}$and $R_{\perp}$, the more dramatic the apparent electrical anisotropy. More de- tailed descriptions of the ANISBEDS model are available from Lüling et al. (1994) and Anderson (2001).

The model requires inputs of $R_{\|}$and $R_{\perp}$ and calculates the propa-

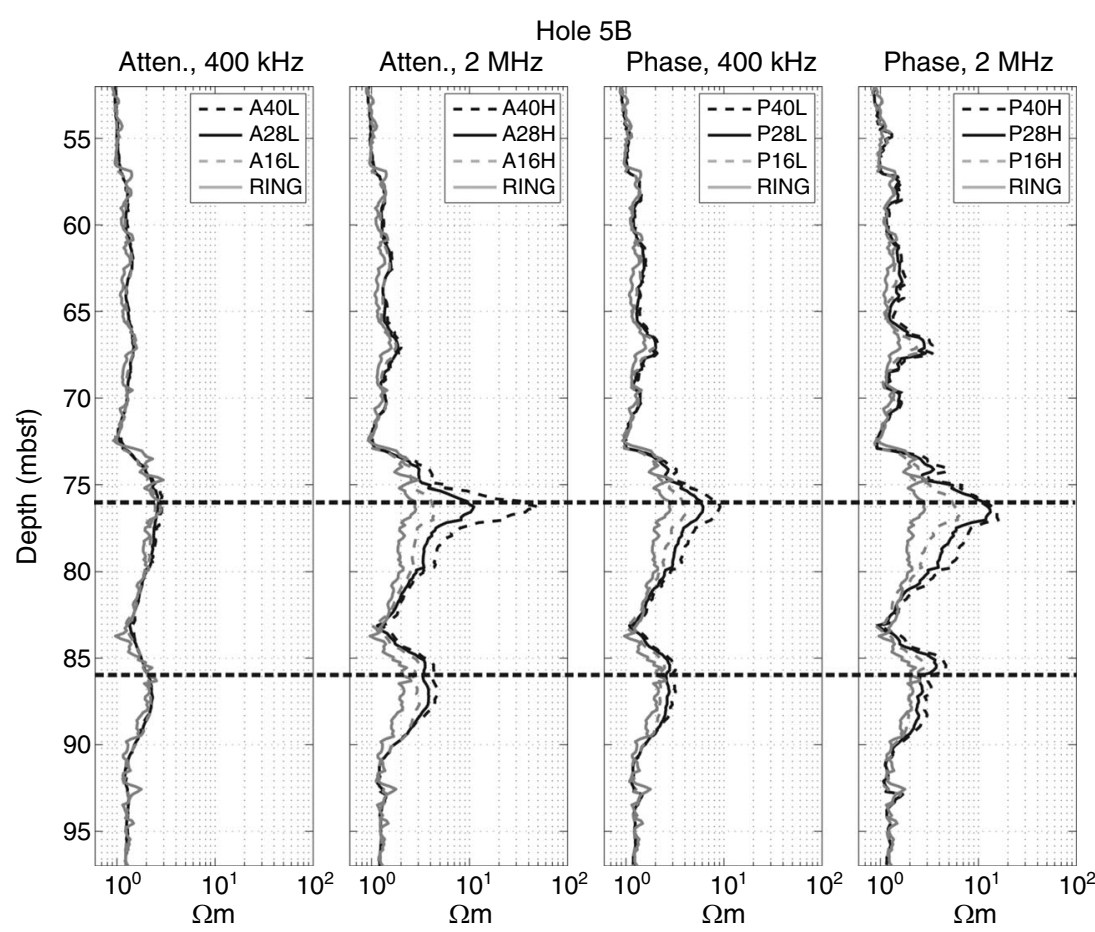

Figure 9. Propagation resistivity curves measured in NGHP-01 Hole 5B. Gas hydratefilled fractures were identified from 55 to 90 mbsf, which coincides with propagation curve separations. Depths highlighted with thick dashed lines were modeled.

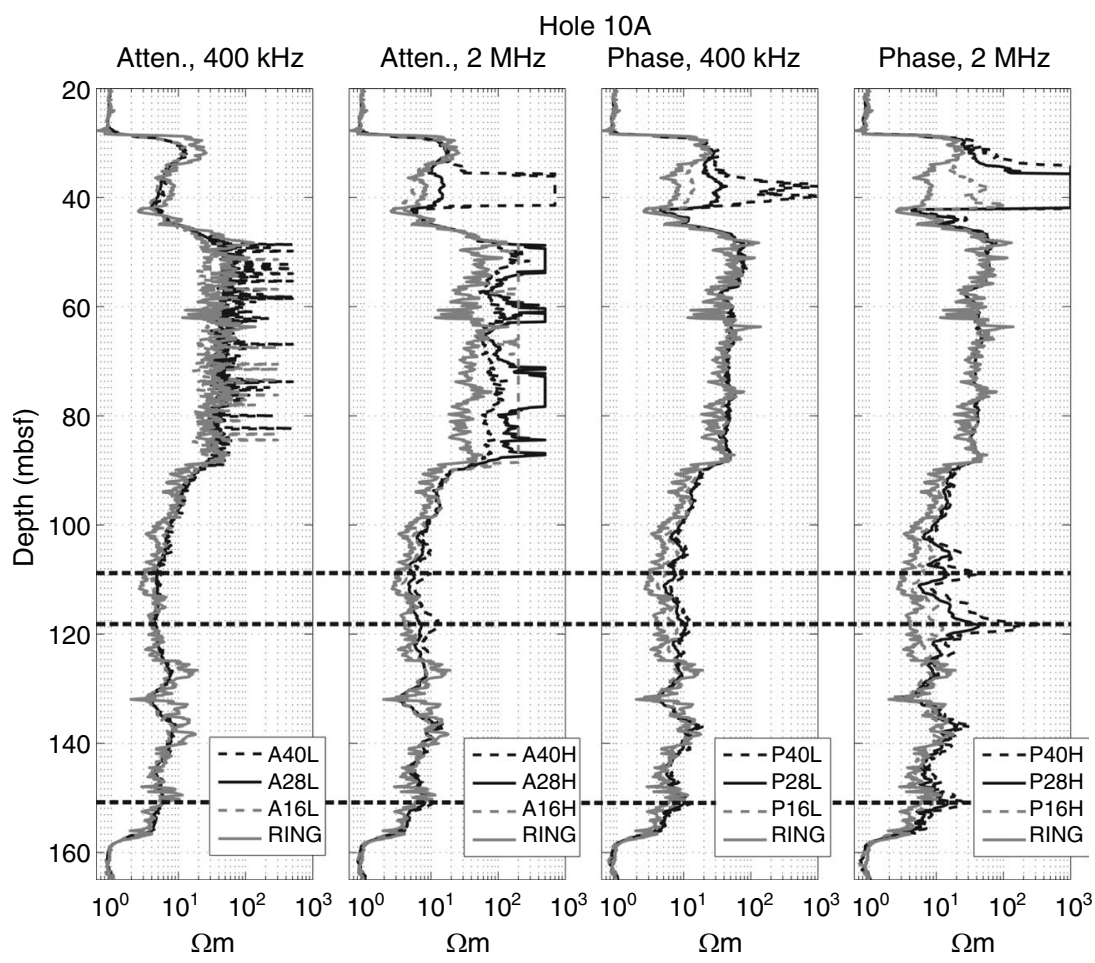

Figure 10. Propagation resistivity curves measured in NGHP-01 Hole 10A. Gas hydratefilled fractures were identified from 29 to $152 \mathrm{mbsf}$. Depths highlighted with thick dashed lines were modeled. 
gation resistivity measurement response for laminated formations dipping from $60^{\circ}$ to $90^{\circ}$ at $400-\mathrm{kHz}$ and $2-\mathrm{MHz}$ frequencies. $R_{\|}$and $R_{\perp}$ can be calculated from four components: background formation resistivity $R_{b}$, gas hydrate resistivity $R_{\text {hyd }}$, hydrate volume fraction $V_{\text {hyd }}$, and formation volume fraction $1-V_{\text {hyd }}$.

$$
\begin{gathered}
R_{\perp}=R_{\text {hyd }} V_{\text {hyd }}+\left(1-V_{\text {hyd }}\right) R_{b} \\
R_{\|}=\left(\frac{V_{\text {hyd }}}{R_{\text {hyd }}}+\frac{\left(1-V_{\text {hyd }}\right)}{R_{b}}\right)^{-1}
\end{gathered}
$$

The input value for $R_{b}$ and range of values for $R_{\text {hyd }}$ and $V_{\text {hyd }}$ were constrained from known information on each parameter. $R_{b}$ is set equal to $1.15 \Omega \mathrm{m}$ based on the average calculated water-saturated resistivity for the intervals of interest in the NGHP-01 holes. A large range is used for $V_{\text {hyd }}$ - from little more than $1 \%$ hydrate to saturations as high as $50 \%$ at Site 5 and $100 \%$ at Site 10 .

However, $R_{\text {hyd }}$ is poorly constrained. Pure laboratory-formed methane hydrate is an excellent electrical insulator (Davidson, 1983). Natural gas hydrate in marine sediments is likely not a perfect electrical insulator. X-ray images of pressure cores from the KG basin reveal noncontinuous planes with changes in gas hydrate thickness and occurrence (Collett et al., 2008; Holland et al., 2008) that look more like sinuous webs than solid planes. In addition, as gas hydrate forms, in situ low-resistivity brine-filled pathways may be trapped in the system (Camps et al., 2008) and decrease the bulk resistivity. For the model, $R_{\text {hyd }}$ was loosely constrained from 50 to $1200 \Omega \mathrm{m}$.

Based on the constraints on $R_{\text {hyd }}$ and $V_{\text {hyd }}$, we modeled a range of inputs of $R_{\|}$and $R_{\perp}$. Each modeled scenario outputs twelve resistivity curves, (six phase and six attenuation curves) at three different source and receiver spacings and at two frequencies $(2 \mathrm{MHz}$ and $400 \mathrm{kHz}$ ). Each curve varies depending on fracture angle (Figure $11)$.

To determine the best-matching scenario between the measured resistivity and the modeled resistivity, seven test depths were selected within the fractured $\mathrm{HBI}$ in Holes $5 \mathrm{~A}, 5 \mathrm{~B}$, and $10 \mathrm{~A}$ with varying degrees of curve separation and different average fracture dips. Average fracture dips were calculated spherically based on the selected fractures $\pm 2.5 \mathrm{~m}$ from each test depth. Each selected depth is highlighted with a red dashed line in Figures 8-10. To quantify the difference for a specific depth between the twelve measured values, $R_{i}^{\text {meas }}$, and the twelve modeled values at a specific average dip, $R_{i}^{\text {mod }}$, the fractional variance $\sigma$ was calculated as

$$
\sigma=\sqrt{\sum_{i}^{12}\left(\frac{R_{i}^{\text {meas }}-R_{i}^{\text {mod }}}{R_{i}^{\text {meas }}}\right)^{2}} .
$$

Table 1. Accuracy limits for propagation resistivity measurements from Schlumberger (2008).

\begin{tabular}{lc}
$\begin{array}{l}\text { Resistivity } \\
\text { Curves }\end{array}$ & $\begin{array}{c}\text { Accuracy Limit } \\
(\text { ohm*m) }\end{array}$ \\
\hline A-L & 10 \\
A-H & 50 \\
P-L & 100 \\
P-H & 3000 \\
\hline
\end{tabular}

Using equation 5 for every modeled scenario, each test depth was considered independently and additional scenarios were modeled to minimize the fractional variance at each test depth. The $\sigma$ parameter is reported with each test depth in Tables 2-4.
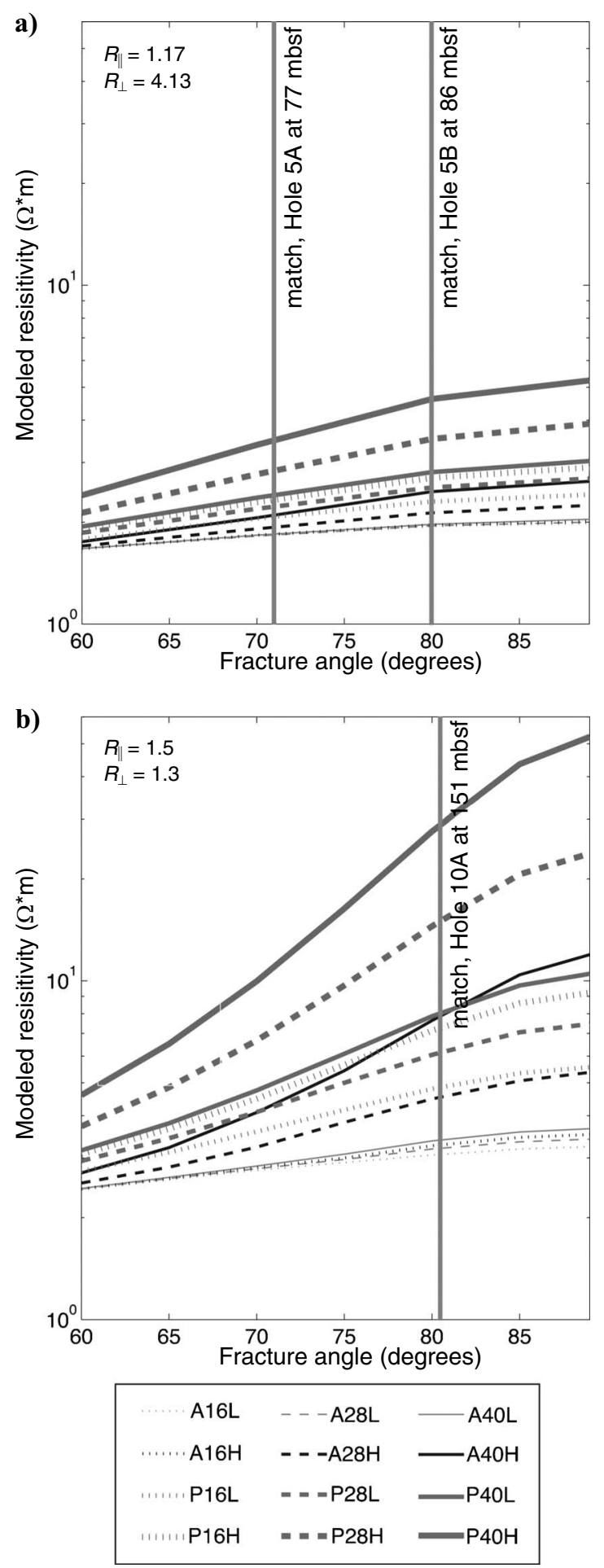

Figure 11. Modeled ANISBEDS scenario outputs for (a) $R_{\|}=1.17$ and $R_{\perp}=4.13$ and (b) $R_{\|}=1.5$ and $R_{\perp}=13$. The scenario (a) has two matches with the measured data, for Hole $5 \mathrm{~A}$ at $77 \mathrm{mbsf}$ and in Hole 5B at 86 mbsf. Each match is indicated with a thick vertical line. The scenario (b) has one match for Hole 10A at $151 \mathrm{mbsf}$. 


\section{RESULTS AND DISCUSSION}

In general, modeled resistivity values reproduce curve separations observed in the measured resistivity data (Tables 2-4). For instance, all resistivity values, both measured and modeled, tend to increase as the transmitter-receiver spacing increases. In addition, phase-shift measurements tend to be higher than the attenuation measurement at the same frequency and transmitter-receiver spacing. This response is expected with near-vertical fractures because phase-shift measurements are more sensitive to vertical features and attenuation measurements are more sensitive to horizontal features (Anderson, 2001).

Figure 11 demonstrates two selected best-match scenarios that include a match at $77 \mathrm{mbsf}$ for Hole 5A, $86 \mathrm{mbsf}$ for Hole 5B, and 151 mbsf for Hole 10A. In all of the models, the resistivity values and the separation between the curves increases with fracture angle. Similar to the measured data, the modeled $\mathrm{P} 40 \mathrm{H}$ curve produces the highest resistivities.

The modeling results can also be used to calculate a single value of hydrate saturation and gas hydrate resistivity at each depth (equations 3 and 4). These estimates can be seen at the bottom of Tables $2-4$, as well as a comparison with Archie's equation estimates from Figures 3 and 4. Gas hydrate saturation derived from the model are lower than the gas hydrate saturation calculated using Archie's equation at five of the seven depths. These results indicate that Archie's

Table 2. Measured and modeled propagation resistivity values at selected depths in Hole $5 \mathrm{~A}$, as well as the average dip, the best match model $\sigma, R, R_{\|}$, and calculated $\boldsymbol{R}_{\text {hyd }}$. Measured propagation resistivity logs from Hole 5A appear in Figure 8.

Hole 5A

\begin{tabular}{|c|c|c|c|c|}
\hline \multirow[b]{2}{*}{ Curve } & \multicolumn{2}{|c|}{$77 \mathrm{mbsf}, 71^{\circ} \mathrm{dip}$} & \multicolumn{2}{|c|}{$90 \mathrm{mbsf}, 73^{\circ} \mathrm{dip}$} \\
\hline & $\begin{array}{l}\text { Measured } \\
\text { Resistivity } \\
(\text { ohm* m) }\end{array}$ & $\begin{array}{l}\text { Modeled } \\
\text { Resistivity } \\
\left(\mathrm{ohm}^{*} \mathrm{~m}\right)\end{array}$ & $\begin{array}{l}\text { Measured } \\
\text { Resistivity } \\
(\text { ohm* m) }\end{array}$ & $\begin{array}{l}\text { Modeled } \\
\text { Resistivity } \\
(\text { ohm* m) }\end{array}$ \\
\hline A16L & 2.0 & 1.8 & 2.8 & 2.9 \\
\hline A28L & 2.0 & 1.8 & 2.9 & 3.0 \\
\hline A40L & 2.1 & 1.8 & 3.2 & 3.1 \\
\hline $\mathrm{A} 16 \mathrm{H}$ & 2.6 & 1.8 & 5.0 & 3.0 \\
\hline $\mathrm{A} 28 \mathrm{H}$ & 2.9 & 1.9 & 13 & 3.8 \\
\hline $\mathrm{A} 40 \mathrm{H}$ & 3.3 & 2.1 & 111 & 5.5 \\
\hline P16L & 2.3 & 2.1 & 3.7 & 4.1 \\
\hline P28L & 2.6 & 2.2 & 6.2 & 5.0 \\
\hline P40L & 3.0 & 2.4 & 10 & 6.1 \\
\hline $\mathrm{P} 16 \mathrm{H}$ & 2.5 & 2.3 & 4.3 & 5.6 \\
\hline $\mathrm{P} 28 \mathrm{H}$ & 3.4 & 2.8 & 9.2 & 9.8 \\
\hline $\mathrm{P} 40 \mathrm{H}$ & 4.3 & 3.5 & 14 & 17 \\
\hline & \multicolumn{2}{|c|}{$\begin{array}{c}S_{\mathrm{h}}^{\mathrm{a}}=25 \% S_{\mathrm{h}}^{\mathrm{b}}=2.8 \% \\
\mathrm{R}_{\|}=1.17 ; \mathrm{R}_{\perp}=4.13 \\
\sigma=2.0 ; \mathrm{R}_{\mathrm{hyd}}=174 \text { ohm*m }\end{array}$} & \multicolumn{2}{|c|}{$\begin{array}{c}S_{\mathrm{h}}^{\mathrm{a}}=41 \% S_{\mathrm{h}}^{\mathrm{b}}=43 \% \\
\mathrm{R}_{\|}=1.5 ; \mathrm{R}_{\perp}=15 \\
\sigma=8.1 ; \mathrm{R}_{\text {hyd }}=59 \text { ohm } * \mathrm{~m}\end{array}$} \\
\hline
\end{tabular}

\footnotetext{
${ }^{\mathrm{a}}$ Gas hydrate saturation calculated via Archie's equation using RING resistivity and $n=2$ as shown in Figure 3 .

${ }^{\mathrm{b}} \mathrm{Gas}$ hydrate saturation calculated from the best match model parameters using equations 3 and 4 and in situ porosity.
}

equation generally overestimates gas hydrate saturation in vertical fractures and confirm similar conclusions made by Lee and Collett (2009)

In the model scenarios, the values of $R_{\text {hyd }}$ were allowed to range beyond $1000 \Omega \mathrm{m}$; however, each best-match scenario tended to have much lower values of $R_{\text {hyd }}$ between 50 and $200 \Omega \mathrm{m}$. Above approximately $200 \Omega \mathrm{m}$, the curves separate too much to match the measured resistivity data. Thus, in situ gas hydrate likely has a resistivity between 50 and $200 \Omega \mathrm{m}$.

\section{Site 5}

At two depths, 77 mbsf in Hole 5A and 86 mbsf in Hole 5B, gas hydrate saturations determined by the model are $2.8 \%$ and $3.2 \%$, respectively, an order of magnitude less than the hydrate saturation calculated using Archie's equation (Tables 2 and 3). The best match at both depths is the same, and $R_{\|}=1.17$ and $R_{\perp}=4.13$ (Figure 11). Measured and modeled values for 77 and $86 \mathrm{mbsf}$ were low: None of the measured values from the 12 curves exceeded $5 \Omega \mathrm{m}$ (Tables 2 and 3). Similarly, in Hole 5A, the measured propagation resistivity curves did not exceed $5 \Omega \mathrm{m}$ in a total of $23 \mathrm{~m}$ of the $39-\mathrm{m}$ HBI (Figure 8 ). In Hole $5 \mathrm{~B}$, the measured propagation resistivity curves do not exceed $5 \Omega \mathrm{m}$ in $25 \mathrm{~m}$ of the $35-\mathrm{m} \mathrm{HBI}$ (Figure 9). These low resistivity measurements likely indicate low gas hydrate saturations $(<4 \%)$ in these fractured sediments, regardless of the fracture dip

Table 3. Measured and modeled propagation resistivity values at selected depths in Hole $5 \mathrm{~B}$, as well as the average dip, the best match model $\sigma, R, R_{\|}$, and $R_{\text {hyd }}$. Measured propagation resistivity logs from Hole 5B appear in Figure 9.

Hole 5B

\begin{tabular}{|c|c|c|c|c|}
\hline \multirow[b]{2}{*}{ Curve } & \multicolumn{2}{|c|}{$76 \mathrm{mbsf}, 83^{\circ} \mathrm{dip}$} & \multicolumn{2}{|c|}{$86 \mathrm{mbsf}, 80^{\circ} \mathrm{dip}$} \\
\hline & $\begin{array}{l}\text { Measured } \\
\text { Resistivity } \\
(\text { ohm* m) }\end{array}$ & $\begin{array}{l}\text { Modeled } \\
\text { Resistivity } \\
\left(\text { ohm* m) }^{*} \text { m }\right.\end{array}$ & $\begin{array}{l}\text { Measured } \\
\text { Resistivity } \\
\left(\mathrm{ohm}^{*} \mathrm{~m}\right)\end{array}$ & $\begin{array}{l}\text { Modeled } \\
\text { Resistivity } \\
\left(\text { ohm }^{*} \mathrm{~m}\right)\end{array}$ \\
\hline A16L & 2.4 & 2.6 & 1.8 & 1.9 \\
\hline A28L & 2.6 & 2.7 & 1.8 & 2.0 \\
\hline A40L & 2.9 & 2.8 & 1.8 & 2.0 \\
\hline $\mathrm{A} 16 \mathrm{H}$ & 4.1 & 2.8 & 3.0 & 2.0 \\
\hline $\mathrm{A} 28 \mathrm{H}$ & 9.9 & 3.7 & 3.5 & 2.1 \\
\hline $\mathrm{A} 40 \mathrm{H}$ & 38 & 5.9 & 4.1 & 2.5 \\
\hline P16L & 3.8 & 3.9 & 2.4 & 2.3 \\
\hline P28L & 5.9 & 4.8 & 2.7 & 2.5 \\
\hline P40L & 8.9 & 6.1 & 3.0 & 2.8 \\
\hline $\mathrm{P} 16 \mathrm{H}$ & 5.5 & 5.6 & 2.7 & 2.7 \\
\hline $\mathrm{P} 28 \mathrm{H}$ & 11 & 10 & 3.6 & 3.5 \\
\hline $\mathrm{P} 40 \mathrm{H}$ & 13 & 18 & 4.5 & 4.6 \\
\hline & \multicolumn{2}{|c|}{$\begin{array}{c}\mathrm{S}_{\mathrm{h}}{ }^{\mathrm{a}}=24 \% \mathrm{~S}_{\mathrm{h}}{ }^{\mathrm{b}}=20 \% \\
\mathrm{R}_{\|}=1.3 ; \mathrm{R}_{\perp}=8.6 \\
\sigma=6.3 ; \mathrm{R}_{\mathrm{hyd}}=640 \mathrm{ohm}^{*} \mathrm{~m}\end{array}$} & \multicolumn{2}{|c|}{$\begin{array}{c}\mathrm{S}_{\mathrm{h}}{ }^{\mathrm{a}}=33 \% \mathrm{~S}_{\mathrm{h}}{ }^{\mathrm{b}}=3.2 \% \\
\mathrm{R}_{\|}=1.17 ; \mathrm{R}_{\perp}=4.13 \\
\sigma=1.9 ; \mathrm{R}_{\text {hyd }}=174 \text { ohm } * \mathrm{~m}\end{array}$} \\
\hline
\end{tabular}

\footnotetext{
${ }^{a}$ Gas hydrate saturation calculated via Archie's equation using RING resistivity and $n=2$ as shown in Figure 3 .

${ }^{\mathrm{b}} \mathrm{Gas}$ hydrate saturation calculated from the best match model parameters using equations 3 and 4 and in situ porosity.
} 
angle. Gas hydrate saturations of just a few percent agree with the estimates from chlorinity and pressure core measurements at Site 5 (Figure 3).

At 90 mbsf in Hole 5A and at 76 mbsf in Hole 5B, higher gas hydrate saturations are predicted by the model, reaching $43 \%$ and $20 \%$, respectively, and are quite similar to the Archie saturations of $41 \%$ and $24 \%$. The similar saturations suggest that Archie's equation may be valid even in anisotropic media under certain conditions. These depths, 90 mbsf in Hole 5A and 76 mbsf in Hole 5B, are notable sections of the log, where the largest curve separations and highest resistivity were measured at Site 5.

The measured resistivity values at $90 \mathrm{mbsf}$ in Hole 5A and 76 mbsf in Hole 5B have similar magnitudes. Besides hydrate saturation, the most significant difference between the two depths is the average dip angle, $73^{\circ}$ at $90 \mathrm{mbsf}$ and $83^{\circ}$ at $76 \mathrm{mbsf}$. Thus, as the measured resistivity and curve separation increase, dip angle becomes a significant component to determining the best matching scenario and hydrate saturation.

\section{Site 10}

Measured and modeled resistivity values at Site 10 are significantly higher than at Site 5. Two of the three modeled depths (at 109 and $151 \mathrm{msbf}$ ) produce gas hydrate saturations of $20 \%$ and $41 \%$ respectively, which are far lower than the gas hydrate saturations calculated by Archie's equation ( $41 \%$ and $61 \%$ ) (Table 4$)$. The hydrate saturation at 109 and $151 \mathrm{mbsf}$, determined from the model, are close to chlorinity and pressure core gas hydrate saturations from Holes 10B and 10D (Figure 4). In addition, the moderate measured resistivities $(<40 \Omega \mathrm{m})$ recorded at 109 and $151 \mathrm{mbsf}$ are similar to resistivities measured in most of the interval below $90 \mathrm{mbsf}$, except for $4 \mathrm{~m}$ from 116 to $120 \mathrm{mbsf}$.

Dip angle can significantly influence saturation at Site 10. For example, while measured resistivities at 151 mbsf were slightly lower than the measured resistivities at 109 mbsf, the modeled hydrate saturation was significantly higher at $151 \mathrm{mbsf}$ because the average dip angle was $81^{\circ}$, as opposed to $73^{\circ}$ at $109 \mathrm{mbsf}$ (Table 4). However, the average dip for the interval below 90 mbsf in Hole 10A is relatively low $\left(70^{\circ}\right)$ and coupled with moderate resistivities, gas hydrate saturations for most of the interval below 90 mbsf in Hole 10A could be $20 \%$ or less and likely not greater than $40 \%$.

The greatest resistivity curve separation occurs at $118 \mathrm{mbsf}$ in Hole 10A (Figure 10). The model predicts a hydrate saturation of 96\% at this depth, twice that calculated using Archie's equation. This is the only location where the model predicts saturation significantly greater than Archie's equation and is substantially higher than pressure core measurements $\left(S_{h} \sim 20-30 \%\right)$ and chlorinity estimates $\left(S_{h}<20 \%\right)$ at Site 10 . We also observe that the fractures near 118 mbsf have relatively low dip angles of approximately $70^{\circ}$. Higher dip angles result in higher resistivities, but it appears that high dip angle is not the primary influence on high measured resistivity in this case. Possibly, the resistivity images in this interval may underestimate the number of fractures. LWD resistivity images investigate up to $13 \mathrm{~cm}$ into the formation while the 2-MHz propagation resistivity measurements penetrate $46-76 \mathrm{~cm}$ (Schlumberger, 2007). In this instance, high-angle fractures could exist $46-76 \mathrm{~cm}$ from the borehole wall but not intersect it; these would be measured as high-resistivity fractures by the propagation resistivity but not be visible in the

Table 4. Measured and modeled propagation resistivity values at selected depths in Hole 10A, as well as the average dip, the best match model $\sigma, R, R_{\|}$, and calculated $R_{\text {hyd }}$. Measured propagation resistivity logs from Hole 10A appear in Figure 10.

Hole 10A

\begin{tabular}{|c|c|c|c|c|c|c|}
\hline \multirow[b]{2}{*}{ Curve } & \multicolumn{2}{|c|}{$109 \mathrm{mbsf}, 73^{\circ} \mathrm{dip}$} & \multicolumn{2}{|c|}{$118 \mathrm{mbsf}, 70^{\circ} \mathrm{dip}$} & \multicolumn{2}{|c|}{$151 \mathrm{mbsf}, 81^{\circ} \mathrm{dip}$} \\
\hline & $\begin{array}{l}\text { Measured } \\
\text { Resistivity } \\
\text { (ohm* m) }\end{array}$ & $\begin{array}{l}\text { Modeled } \\
\text { Resistivity } \\
(\text { ohm* m) }\end{array}$ & $\begin{array}{l}\text { Measured } \\
\text { Resistivity } \\
\text { (ohm* m) }\end{array}$ & $\begin{array}{l}\text { Modeled } \\
\text { Resistivity } \\
(\text { ohm* m) }\end{array}$ & $\begin{array}{l}\text { Measured } \\
\text { Resistivity } \\
(\text { ohm* m) }\end{array}$ & $\begin{array}{l}\text { Modeled } \\
\text { Resistivity } \\
(\text { ohm* m) }\end{array}$ \\
\hline A16L & 2.7 & 4.3 & 4.2 & 4.9 & 5.0 & 3.1 \\
\hline A28L & 2.8 & 4.4 & 4.4 & 5.0 & 5.5 & 3.2 \\
\hline $\mathrm{A} 40 \mathrm{~L}$ & 3.0 & 4.5 & 4.8 & 5.0 & 5.9 & 3.4 \\
\hline $\mathrm{A} 16 \mathrm{H}$ & 2.9 & 4.4 & 4.6 & 5.0 & 6.4 & 3.3 \\
\hline A28H & 4.5 & 5.8 & 6.6 & 5.7 & 7.8 & 4.6 \\
\hline $\mathrm{A} 40 \mathrm{H}$ & 11 & 9.9 & 14 & 7.0 & 9.9 & 8.2 \\
\hline P16L & 4.5 & 7.0 & 7.1 & 7.0 & 7.6 & 4.9 \\
\hline P28L & 6.0 & 8.8 & 10 & 8.1 & 10 & 6.3 \\
\hline $\mathrm{P} 40 \mathrm{~L}$ & 8.5 & 10 & 14 & 9.4 & 12 & 8.2 \\
\hline $\mathrm{P} 16 \mathrm{H}$ & 7.5 & 10 & 11 & 8.8 & 8.7 & 7.4 \\
\hline $\mathrm{P} 28 \mathrm{H}$ & 19 & 24 & 34 & 14 & 15 & 16 \\
\hline \multirow[t]{2}{*}{$\mathrm{P} 40 \mathrm{H}$} & 36 & 66 & 188 & 22 & 26 & 31 \\
\hline & \multicolumn{2}{|c|}{$\begin{array}{c}\mathrm{S}_{\mathrm{h}}{ }^{\mathrm{a}}=41 \% \mathrm{~S}_{\mathrm{h}}^{\mathrm{b}}=20 \% \\
\sigma=3.6 ; \mathrm{R}_{\|}=1.3 ; \mathrm{R}_{\perp}=25 \\
\mathrm{R}_{\mathrm{hyd}}=204 \mathrm{ohm} * \mathrm{~m}\end{array}$} & \multicolumn{2}{|c|}{$\begin{array}{c}\mathrm{S}_{\mathrm{h}}{ }^{\mathrm{a}}=48 \% \mathrm{~S}_{\mathrm{h}}{ }^{\mathrm{b}}=96 \% \\
\sigma=6.7 ; \mathrm{R}_{\|}=2.5 ; \mathrm{R}_{\perp}=50 \\
\mathrm{R}_{\mathrm{hyd}}=90 \mathrm{ohm}^{*} \mathrm{~m}\end{array}$} & \multicolumn{2}{|c|}{$\begin{array}{c}\mathrm{S}_{\mathrm{h}}{ }^{\mathrm{a}}=61 \% \mathrm{~S}_{\mathrm{h}}^{\mathrm{b}}=41 \% \\
\sigma=5.7 ; \mathrm{R}_{\|}=1.5 ; \mathrm{R}_{\perp}=13 \\
\mathrm{R}_{\mathrm{hyd}}=51 \mathrm{ohm}^{*} \mathrm{~m}\end{array}$} \\
\hline
\end{tabular}

${ }^{\mathrm{a}}$ Gas hydrate saturation calculated via Archie's equation using RING resistivity and $n=2$ as shown in Figure 4.

${ }^{\mathrm{b}}$ Gas hydrate saturation calculated from the best match model parameters using equations 3 and 4 and in situ porosity. 
shallow-penetrating resistivity images. Alternatively, the hydrate accumulation near 118 mbsf in Hole 10A may contain large gas hydrate nodules or pore-filling gas hydrate.

\section{Horizontal fractures and thin horizontal layers}

One striking difference between the measured and modeled resistivity values at Site 5 is the $\mathrm{A} 40 \mathrm{H}$ curve, and to a lesser extent, the $\mathrm{A} 28 \mathrm{H}$ and $\mathrm{A} 16 \mathrm{H}$ curves. At every depth from Site 5, the measured $\mathrm{A} 40 \mathrm{H}$ curve is higher than the modeled curve Tables 2 and 3. In addition, the measured curve is significantly higher than the modeled curve at the depths exhibiting higher resistivity. For example, at 90 mbsf in Hole 5A, the A40H curve measures $111 \Omega \mathrm{m}$, but the modeled curve reaches only $5.5 \Omega \mathrm{m}$. The same characteristic behavior is not seen in the $\mathrm{A} 40 \mathrm{H}$ curves from Site 10.

In high-angle fracture environments, phase-shift measurements should exceed attenuation measurements collected at the same frequency and transmitter-receiver spacing because phase-shift measurements are more sensitive to vertical features and attenuation measurements are more sensitive to horizontal features (Anderson, 2001). An attenuation curve exceeding the phase-shift curve at the same frequency and transmitter-receiver separation suggests a significant amount of near-horizontal fractures or thin, resistive layers coexisting at that depth. Nearly horizontal fractures were visible in the pressure core from Hole 10B and a few were identified from the LWD images in Hole 10A, but none were visible in the LWD images at Site 5. Millimeter-sized horizontal gas hydrate-filled fractures or thin, hydrate-filled sand lenses would likely not be visible on an LWD image because the feature is below the vertical resolution of the image. The behavior of the $\mathrm{A} 40 \mathrm{H}$ measurement suggests many near-horizontal gas hydrate-filled fractures or thin hydrate-filled sand lenses may be present at Site 5, perhaps more than occur at Site 10 .

Nearly horizontal gas hydrate-filled fractures that open only a few millimeters or thin permeable sand laminations may occur frequently within the gas hydrate stability zone but go unnoticed by traditional logging tools in vertical holes that only measure resistivity perpendicular to the borehole.

\section{Comparison between measured and modeled resistivity}

Differences between the measured and modeled resistivity could be caused by any of the model input parameters, such as $R_{b}, R_{\text {hyd }}$, $V_{\text {hyd }}$, and/or the calculated average fracture angle. In addition, the model uses many approximations of the natural environment. For example, in the model, gas hydrate only resides within the fracture planes, yet a small amount of the intergranular pore space may contain gas hydrate. Gas hydrate in the pore space could be effectively accounted for by raising the background resistivity input into the model. However, the model results would still only provide saturation estimates of hydrate exclusively within the fracture planes and skew the modeled gas hydrate resistivity. The model also assumes that the fractures extend infinitely, but another study at NGHP-01 Site 5 suggests fractures only extend a few meters (Cook and Goldberg, 2008b). Finally, the model does not consider features visible from the NGHP-01 pressure core X-ray; that is, wispy gas hydratefilled veins (Holland et al., 2008).

Although the model represents the natural gas hydrate system with imperfect constraints, we are able to compute model scenarios at seven depths that replicate the measured propagation resistivities at each depth with a relatively low fractional variance (equation 5).
We believe the results reasonably reproduce natural phenomena at the NGHP-01 sites and conclude that electrical anisotropy caused by the near-vertical gas hydrate-filled fractures significantly affects the resistivity measurements.

\section{Resource potential at Site $\mathbf{1 0}$}

Gas hydrate saturations at NGHP-01 Site 10 from modeling, pressure cores, and chlorinity measurements suggest gas hydrate saturations between $15 \%$ and $40 \%$ from 90 to 155 mbsf. Between 45 and 90 mbsf, propagation resistivity measurements do consistently not separate in Hole 10A, possibly suggesting gas hydrate is not only in the fractures but also occupies the primary pore space. Resistivity measurements in that interval range between 100 and $200 \Omega \mathrm{m}$, similar to the model estimates for the resistivity of in situ natural gas hydrate; thus, this may be completely saturated with gas hydrate, or massive gas hydrate could be present in hole. With porosities near or above 50\% throughout Hole 10A (Collett et al., 2008), NGHP-01 Site 10 is a significant store of natural gas hydrates and could be economic depending on the lateral extent of the hydrate accumulation.

\section{Potential impact of directional resistivity measurements}

While the results of the ANISBEDS modeling are encouraging, significant assumptions are made in the model scenarios, specifically for the boundaries of $V_{h}, R_{h}$, and to a lesser extent $R_{b}$. New logging tools that measure directional resistivity could reduce the guesswork used in determining model parameters by directly measuring $R_{\|}$and $R_{\perp}$ (Kennedy et al., 2001; Li et al., 2005; Lee and Collett, 2009). The application of these new tools in a gas hydrate-filled fracture environment would not only further aid in the characterization of electrical anisotropy and in the calculation of gas hydrate saturation, but also may help determine a ratio for gas hydrate residing in intergranular pore space to fracture fill. In addition, directional resistivity measurements should clarify the occurrence of horizontal or nearhorizontal gas hydrate-filled fractures.

\section{CONCLUSIONS}

We show that electrical anisotropy due to the presence of nearly vertical gas hydrate-filled fractures is a credible explanation for the curve separations in the propagation resistivity measurements from NGHP-01. When resistivity images are not available, separation in the propagation resistivity curves measured in vertical boreholes can be used to identify intervals containing near-vertical gas hydratefilled fractures. We also conclude

- Near-vertical gas hydrate-filled fractures result in high measured resistivities in vertical holes.

- If Archie's equation is applied to near-vertical, gas hydrate-filled fracture intervals, in situ gas hydrate saturation is likely overestimated.

- The model results suggest that in situ natural gas hydrate is not a perfect electrical insulator and that natural gas hydrate resistivity is likely between 50 and $200 \Omega \mathrm{m}$.

- Modeled resistivities at NGHP-01 Site 5 suggest in situ gas-hydrate saturations for most of the hole on the order of $4 \%$ or less. These gas hydrate saturation are closer to pressure core and chlorinity measurement estimates at the site.

- At NGHP-01 Site 5, more gas hydrate-filled near-horizontal frac- 
tures or thin hydrate-filled sand lenses may occur than near-vertical fractures.

- At NGHP-01 Site 10, pressure cores, chlorinity measurements, and modeling suggest gas hydrate saturations between $15 \%$ and $40 \%$ from 90 to 155 mbsf. With porosities near $50 \%$, Site 10 could have resource potential depending on the lateral extent of the hydrate accumulation.

\section{ACKNOWLEDGMENTS}

We thank the Directorate General of Hydrocarbons in India and the Ministry of Petroleum in India for allowing the use of data collected during NGHP-01. We are grateful for the efforts of the expedition planners, co-chiefs, crew, and science party of the JOIDES Resolution during NGHP-01. We thank Schlumberger for the use of their ANISBEDS modeling program. We thank three anonymous reviewers, whose suggestions improved the quality and clarity of this paper. Part of this material is based upon work supported by the Department of Energy, National Energy Technology Laboratory while author A. Cook held a National Research Council Research Associateship Award, under Award Number DE-FC26-05NT42248. Geomapapp bathymetry was used for the location map and is freely available online at http://www.geomapapp.org/. The stereonet-plotting program used for this work was written by Richard Allmendinger and is freely available online at http://www.geo.cornell.edu/ geology/faculty/RWA/programs.html.

\section{REFERENCES}

Anderson, B. I., 2001, Modeling and inversion methods of the interpretation of resistivity logging tool response: Ph.D. dissertation, Delft University.

Archie, G. E., 1942, The electrical resistivity log as an aid in determining some reservoir characteristics: Petroleum Transactions of AIME, 146, 5462.

Boswell, R., T. Collett, M. Frye, D. McConnell, W. Shedd, R. Dufrene, P. Godfriaux, S. Mrozewski, G. Guerin, and A. Cook, 2010, Gulf of Mexico Gas Hydrate Joint Industry Project Leg II: Technical Summary, http://www.netl.doe.gov/technologies/oil-gas/FutureSupply/MethaneHydrates/ JIPLegII-IR/, accessed June 2010.

Camps, A. P., P. D. Jackson, J. F. Williams, A. E. Milodowski, M. A. Lovell, and C. A. Rochelle, 2008, Low-resistance brine pathways through Cascadia Margin sediment-hosted hydrates: Presented at 49th Annual Logging Symposium, Society of Petrophysicists and Well Log Analysts.

Chun, J.-H., Y.-I. Kwon, H.-Y. Lee, H.-J. Kim, J.-H. Kim, Y.-S. Park, C.-W. Jeon, J.-W. Lee, G.-O. An, B.-K. Son, J. Ko, B.-J. Ryu, D. Sunwoo, J.-H Oh, Y. Lee, T.-J. Cheong, J.-Y. Lee, and N.-K. Kang, 2008, Shallow gas hydrate in deep sea sediments in the Ulleung back-arc basin, offshore Korea: Proceedings of the 6 th International Conference on Gas Hydrates.

Clennell, M. B., M. Hovland, J. S. Booth, P. Henry, and W. J. Winters, 1999, Formation of natural gas hydrates in marine sediments 1 . Conceptual model of gas hydrate growth conditioned by host sediment properties: Journal of Geophysical Research, 104, B10, 22985-23003, doi: 10.1029/ 1999JB900175.

Collett T. S. , and J. Ladd, 2000, Detection of gas hydrate with downhole logs and assessment of gas hydrate concentrations (saturations) and gas volumes on the Blake Ridge with electrical resistivity data, in C. K. Paull, ed., Proceedings of the Ocean Drilling Program Scientific Results Leg 164: Ocean Drilling Program Texas A\&M University, 179-191.

Collett, T. S., and M. W. Lee, 2000, Reservoir characterization of marine and permafrost associated gas hydrate accumulations with downhole well logs: Annals of the New York Academy of Sciences, 912, 51-64, doi: 10.1111/j.1749-6632.2000.tb06759.x

Collett, T. S., 2001, A review of well-log analysis techniques used to assess gas-hydrate-bearing reservoirs, in C. K. Paull and W. P. Dillon, eds., Natural gas hydrates: Occurrence, distribution and detection: American Geophysical Union Geophysical Monographs, 124, 189-210.

Collett, T. S., M. Riedel, J. Cochran, R. Boswell, J. Presley, P. Kumar, A. Sathe, A. Sethi, M. Lall, and V. Sibal, 2008, Indian National Gas Hydrate Program Expedition 01 initial reports: Directorate General of Hydrocarbons, Ministry of Petroleum \& Natural Gas (India).

Cook, A. E., 2010, Gas hydrate-filled fracture reservoirs on continental mar- gins: Ph.D. dissertation, Columbia University.

Cook, A. E., and D. Goldberg, 2008a, Stress and gas-hydrate-filled fracture distribution, Krishna-Godavari basin, India: Proceedings of the 6th International Conference on Gas Hydrates, https://circle.ubc.ca/handle/2429/ 1553 , accessed June 2010.

Cook, A. E., and D. Goldberg, 2008b, Extent of gas hydrate filled fracture planes: Implications for in situ methanogenesis and resource potential: Geophysical Research Letters, 35, L15302, doi: 10.1029/2008GL034587.

Cook, A. E., D. Goldberg, and R. L. Kleinberg, 2008, Fracture-controlled gas hydrate systems in the northern Gulf of Mexico: Marine and Petroleum Geology, 25, 932-941, doi: 10.1016/j.marpetgeo.2008.01.013.

Cook, A., G. Guerin, S. Mrozewski, T. Collett, and R. Boswell, 2010, Gulf of Mexico Gas Hydrate Joint Industry Project Leg II: Walker Ridge 313 LWD operations and results, http://www.netl.doe.gov/technologies/oilgas/FutureSupply/MethaneHydrates/JIPLegII-IR/, accessed June 2010.

Davidson, D. W., 1983, Gas hydrate as clathrate ices, in J. Cox, ed., Natural gas hydrates: Properties, occurrence and recovery: Butterworth, 1-16.

Dickens G. R. , P. J. Wallace, C. K. Paull, and W. S. Borowski, 2000, Detection of methane gas hydrate in pressure core sampler (PCS) Volume-pressure-time relations during controlled degassing experiments, in $\mathrm{C}$. K Paull, ed., Proceedings of the Ocean Drilling Program Scientific Results: Ocean Drilling Program Texas A\&M University, 164, 113-126.

Ellis, D. V., and J. M. Singer, 2007, Well logging for earth scientists, 2nd edition, Springer.

Erickson, S. N., and R. D. Jarrard, 1998, Porosity/formation-factor relationships for high-porosity siliciclastic sediments from Amazon Fan: Geophysical Research Letters, 25, 2309-2312, doi: 10.1029/98GL01777.

Guerin, G., A. Cook, S. Mrozewski, T. Collett, and R. Boswell, 2010, Gulf of Mexico Gas Hydrate Joint Industry Project Leg II: Green Canyon 955 LWD operations and results, http://www.netl.doe.gov/technologies/oilgasFutureSupply/MethaneHydrates/JIPLegII-IR/, accessed June 2010.

Hesse, R., and W. E. Harrison, 1981, Gas hydrates (clathrates) causing porewater freshening and oxygen isotope fractionation in deep-water sedimentary sections of terrigenous continental margins: Earth and Planetary Science Letters, 55, 453-462, doi: 10.1016/0012-821X(81)90172-2.

Holland, M., P. Schultheiss, J. Roberts, and M. Druce, 2008, Observed gas hydrate morphologies in marine sediments: Proceedings of the 6th International Conference on Gas Hydrates, https:circle.ubc.ca/handle/2429/ 1201, accessed June 2010.

Hovland, M., D. Lysne, and M. Whitcar, 1995, Gas hydrate and sediment gas composition, Hole982A, in B. Carson, G. K. Westbrook, R. J. Musgrave, and E. Suess, eds., Proceedings of the Ocean Drilling Program Scientific Results, Leg 146: 151-162.

Hyndman, R. D., T. Yuan, and K. Moran, 1999, The concentration of deep sea gas hydrates from downhole electrical resistivity logs and laboratory data: Earth and Planetary Science Letters, 172, 167-177, doi: 10.1016/S0012821 X(99)00192-2.

Jain, A. K., and R. Juanes, 2009, Preferential mode of gas invasion in sediments Grain-scale mechanistic model of coupled multiphase fluid flow and sediment mechanics: Journal of Geophysical Research, 114, B8, B08101, doi: 10.1029/2008JB006002.

Kennedy, W. D., D. C. Herrick, and T. Yao, 2001, Calculating water saturation in electrically anisotropic media: Petrophysics, 42, 118-136.

Kennedy, W. D., and D. C. Herrick, 2004, Conductivity anisotropy in shalefree sandstone: Petrophysics, 45, 38-58.

Kvenvolden, K., and L. Barnard, 1982, Hydrates of natural gas in continental margins, in J. S. Watkins, and C. L. Drake, eds., AAPG Memoir, 631-640.

Kvenvolden, K. A., L. A. Barnard, and D. H. Cameron, 1983, Pressure core barrel: Application to the study of gas hydrates, in R. E. Sheridan and F. M. Gradstein, eds., Initial reports of the deep sea drilling project site 76, U. S Government Printing Office, Washington, 367-375.

Leake, J., and F. Shray, 1991, Logging while drilling keeps horizontal well on small target: Oil \& Gas Journal, 89, 52-59.

Lee, M. W., and T. S. Collett, 2009, Gas-hydrate saturations estimated from fractured reservoir at Site NGHP-01-10, Krishna-Godavari Basin, India: Journal of Geophysical Research, 114, B7, B07102, doi: 10.1029/ 2008JB006237

Li, Q., D. Omeragic, L. Chou, L. Yang, and K. Duong, 2005, New directional electromagnetic tool for proactive geosteering and accurate formation evaluation while drilling: SPWLA 46th Annual Logging Symposium.

Liu, X., and P. B. Flemings, 2007, Dynamic multiphase flow model of hydrate formation in marine sediments: Journal of Geophysical Research, 112, B03101, doi: 0.1029/2005JB004227.

Lüling, M. G., R. A. Rosthal, and F. Shray, 1994, Processing and modeling 2-MHz resistivity tool in dipping, laminated, anisotropic formations: 35 th Annual Logging Symposium, Society of Petrophysicists and Well Log Analysts.

Malinverno, A., M. Kastner, M. E. Torres, and U. G. Wortmann, 2008, Gas hydrate occurrence form pore water chlorinity and downhole logs in a transect across the northern Cascadia margin (Integrated Ocean Drilling Program Expedition 311): Journal of Geophysical Research, 113, B8, B08103, doi: 10.1029/2008JB005702. 
Nimblett, J., and C. Ruppel, 2003, Permeability evolution during the formation of gas hydrates in marine sediments: Journal of Geophysical Research, 108, EPM2.1-EPM2.17, doi: 10.1029/2001JB001650.

Pearson, C. F., P. M. Halleck, P. L. McGuire, R. Hermes, and M. Mathews, 1983, Natural-gas hydrate deposits - A review of in situ properties: Journal of Physical Chemistry, 87, 4180-4185, doi: 10.1021/j100244a041.

Santamarina J. C., and C. Ruppel, 2008, The impact of hydrate saturation on the mechanical, electrical, and thermal properties of hydrate bearing sands, silts and clay: Proceedings of the 6th International Conference on Gas Hydrates, https://circle.ubc.ca/handle/2429/2325, accessed June 2010.

Sassen, R., S. L. Loth, L. Cathles, H. H. Roberts, J. K. Whelan, A. V. Milkov, S. T. Sweets, and D. A. DeFreitas, 2001, Massive vein-filling gas hydrate, Relation to ongoing gas migration from the deep subsurface in the Gulf of Mexico: Marine and Petroleum Geology, 18, 551-560, doi: 10.1016/ S0264-8172(01)00014-9.

Schlumberger, 2007, Ecoscope: Multifunction LWD service, Brochure. Schlumberger, 2008, Drilling tools: Quick reference guide 2008 Edition.

Schultheiss, P., M. Holland, and J. Roberts, 2008, Pressure core analysis The keystone of a gas hydrate investigation: Proceedings of the 6th International Conference on Gas Hydrates. https://circle.ubc.ca/handle/2429/ 1201 , accessed June 2010

Spangenberg, E., 2001, Modeling the influence of gas hydrate content on the electrical properties of porous sediments: Journal of Geophysical Research, 106, B4, 6535-6548, doi: 10.1029/2000JB900434.

Tréhu, A. M., G. Bohrmann, M. E. Torres, and F. S. Colwell, 2003, Drilling gas hydrates on hydrate ridge, Cascadia Continental Margin, Ocean Drilling Program Leg 204 initial reports, in C. K. Paull, ed., Proceedings of the Ocean Drilling Program Scientific Results: Ocean Drilling Program Texas A\&M University, $1-75$

Tréhu, A. M., M. E. Torres, G. Bohrmann, and F. S. Colwell, 2006, Leg 204 synthesis Gas hydrate distribution and dynamics in the central Cascadia accretionary complex, in A. M. Tréhu, G. Bohrmann, M. E. Torres, and F. S. Colwell, eds., Proceedings of the Ocean Drilling Program, Scientific Results: Ocean Drilling Program Texas A\&M University.

Ussler, W. III, and C. K. Paull, 1995, Effects of ion exclusion and isotopic fractionation on pore water geochemistry during gas hydrate formation and decomposition: Geo-Marine Letters, 15, 37-44, doi: 10.1007/ BF01204496.

Ussler, W., and C. K. Paull, 2001, Ion exclusion associated with marine gas hydrate deposits, in C. K. Paull, and W. P. Dillon, eds., Natural gas hydrates: Occurrence, distribution and detection: American Geophysical Union Geophysical Monograph, 124, 41-65.

Weinberger, J. L., and K. M. Brown, 2006, Fracture networks and hydrate distribution at Hydrate Ridge, Oregon: Earth and Planetary Science Letters, 245, 123-136, doi: 10.1016/j.eps1.2006.03.012. 